\title{
CORRECTION
}

View Article Online

View Journal I View Issue

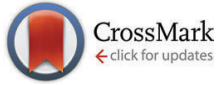

Cite this: Phys. Chem. Chem. Phys., 2014, 16, 21882

www.rsc.org/pccp

\section{Correction: Crystal structure and microstructural changes of molybdenum nitrides traced during catalytic reaction by in situ $\mathrm{X}$-ray diffraction studies}

\author{
Valeria Tagliazucca, ${ }^{a}$ Matteo Leoni ${ }^{\mathrm{b}}$ and Claudia Weidenthaler ${ }^{\star a}$
}

Correction for 'Crystal structure and microstructural changes of molybdenum nitrides traced during catalytic reaction by in situ X-ray diffraction studies' by Valeria Tagliazucca et al., Phys. Chem. Chem. Phys., $2014,16,6182-6188$

Fig. 4 in the original publication does not correspond to the sample discussed. The correct data are shown below.

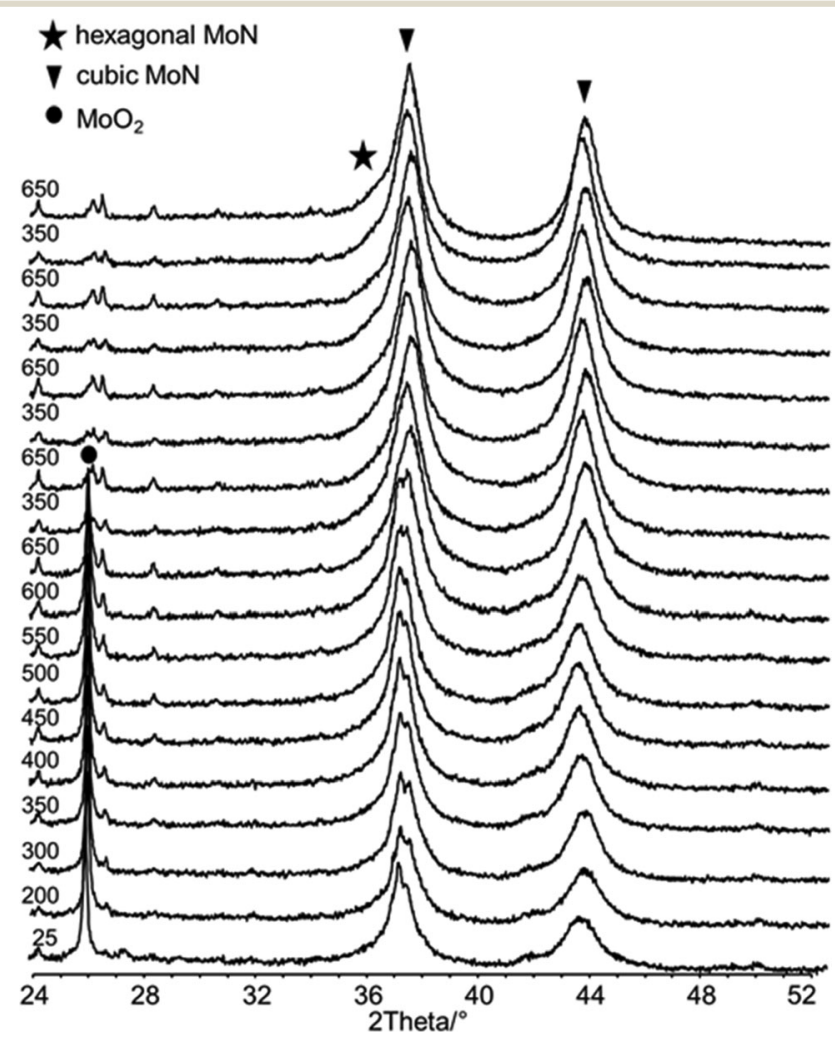

Fig. 4 Selected powder diffraction patterns collected in situ during $\mathrm{NH}_{3}$ decomposition with $\mathrm{MoN}-650$.

The Royal Society of Chemistry apologises for these errors and any consequent inconvenience to authors and readers.

\footnotetext{
${ }^{a}$ Max-Planck-Institut für Kohlenforschung, Kaiser-Wilhelm-Platz 1, 45470 Mülheim an der Ruhr, Germany. E-mail: cweiden@gwdg.de

${ }^{b}$ Department of Civil, Environmental and Mechanical Engineering, University of Trento, via Mesiano, 77-38123 Trento, Italy
} 